\title{
Perioperative evaluation of respiratory impedance using the forced oscillation technique: a prospective observational study
}

Shoko Nakano, Junko Nakahira*, Toshiyuki Sawai, Yosuke Kuzukawa, Junichi Ishio and Toshiaki Minami

\begin{abstract}
Background: Intravascular fluid shifts, mechanical ventilation and inhalational anesthetic drugs may contribute to intraoperative lung injury. This prospective observational study measured the changes in respiratory impedance resulting from inhalational anesthesia and mechanical ventilation in adults undergoing transurethral resection of bladder tumors. The components of respiratory impedance (resistance and reactance) were measured using the forced oscillation technique (FOT).
\end{abstract}

Methods: Respiratory resistance at $5 \mathrm{~Hz}$ (R5) and $20 \mathrm{~Hz}$ (R20), respiratory reactance at $5 \mathrm{~Hz}$ (X5), resonant frequency (Fres) and area of low reactance (ALX) were measured before and immediately after surgery in 30 adults. In addition, preoperative vital capacity (VC), forced vital capacity (FVC) and forced expiratory volume in the first second (FEV1.0) were evaluated using spirometry. All patients were intubated with an endotracheal tube and were mechanically ventilated, with anesthesia maintained with sevoflurane. Pre- and postoperative FOT measurements were compared using Wilcoxon paired rank tests, and the relationships between FOT measurements and preoperative spirometry findings were determined by Spearman's rank correlation analysis.

Results: Twenty-six patients were included in the final analysis: postoperative FOT could not be performed in four because of postoperative restlessness or nausea. The mean duration of surgery was $47 \mathrm{~min}$. All components of respiratory resistance deteriorated significantly over the course of surgery, with median increases in R5, R20, and R5-R20 of $1.67 \mathrm{cmH}_{2} \mathrm{O} / \mathrm{L} / \mathrm{s}(p<0.0001), 1.28 \mathrm{cmH}_{2} \mathrm{O} / \mathrm{L} / \mathrm{s}(p<0.0001)$ and $0.46 \mathrm{cmH}_{2} \mathrm{O} / \mathrm{L} / \mathrm{s}(p=0.0004)$, respectively. The components of respiratory reactance also deteriorated significantly, with $\mathrm{X} 5$ decreasing $1.7 \mathrm{cmH}_{2} \mathrm{O} / \mathrm{L} / \mathrm{s}(p<0.0001)$, Fres increasing $5.57 \mathrm{~Hz}(p<0.0001)$ and ALX increasing $10.51 \mathrm{cmH}_{2} \mathrm{O} / \mathrm{L} / \mathrm{s}(p<0.0001)$. There were statistically significant and directly proportional relationships between pre- and postoperative X5 and \%VC, \%FEV1.0 and \%FVC, with inverse relationships between pre- and postoperative Fres and ALX.

Conclusions: All components measured by FOT deteriorated significantly after a relatively short period of general anesthesia and mechanical ventilation. All components of resistance increased. Of the reactance components, X5 decreased and Fres and ALX increased. Pre- and postoperative respiratory reactance correlated with parameters measured by spirometry.

Trial registration: JMA-IIA00136.

Keywords: Forced oscillation technique, Respiratory impedance, Ventilator-induced lung injury, Mechanical ventilation, General anesthesia

\footnotetext{
* Correspondence: ane052@osaka-med.ac.jp

Department of Anesthesiology, Osaka Medical College, 2-7 Daigaku-machi,

Takatsuki, Osaka 569-8686, Japan
} 


\section{Background}

The forced oscillation technique (FOT) is a non-invasive method of measuring respiratory impedance at rest $[1,2]$. This technique is based on the external application of a pressure wave to the respiratory system, followed by measurement of the resultant airflow. The FOT has entered routine clinical practice for the evaluation and management of patients with obstructive respiratory diseases, including chronic obstructive pulmonary disease (COPD) and asthma [3-6].

Spirometry remains the most frequent method of evaluating preoperative respiratory function; this method, however, is somewhat effort dependent, as it requires the subject to make a maximal forced expiratory maneuver. Therefore, spirometry tends not to be used for postoperative evaluation. Postoperative respiratory function is generally determined by measuring vital signs, such as peripheral oxygen saturation, and, when appropriate, by arterial blood gas analysis. These methods, however, cannot assess postoperative respiratory deterioration. This difficulty may be overcome by using FOT, which requires minimal patient effort. FOT is based on measuring the relationship between pressure waves applied externally to the respiratory system and the resulting respiratory airflow. Impedance of the respiratory system is defined as the ratio of the amplitude of the pressure wave to the amplitude of the resulting flow wave. The FOT measures the two components of respiratory impedance, respiratory resistance (Rrs) and respiratory reactance (Xrs).

A "broadband" FOT device, the MostGraph-01 (Chest MI, Tokyo, Japan), became commercially available in Japan in $2008[5,7]$ and is widely used in pediatric and allergy clinics [8]. This device can measure respiratory impedance, including Rrs and Xrs, using color 3D imaging $[5,9]$. Rrs measured by FOT includes the resistance of the oropharynx, larynx, trachea, large and small airways, lungs and chest wall tissue. By using multiple oscillation frequencies, however, the behaviors of large and peripheral small airways can be distinguished. Sound waves at frequency $<15 \mathrm{~Hz}$ travel more distally, whereas those $>20 \mathrm{~Hz}$ are damped out by intermediate sized airways [10]. Rrs measured at $5 \mathrm{~Hz}$ (R5) and $20 \mathrm{~Hz}$ (R20) are representative of low and high frequency resistance, respectively, with the difference between R5 and R20 (R5 - R20) termed the frequency dependence of Rrs [11]. R5 represents total airway resistance, R20 represents the resistance of the large airways [10], and R5 - R20 can logically reflect the resistance of the small airways. Normal limits for R5 and R20 have not been established. However, a study of the impulse oscillometry system in normal individuals classified resistance oscillation frequencies of $\leq 2 \mathrm{cmH}_{2} \mathrm{O} / \mathrm{L} / \mathrm{s}$ as normal, those between 2 and $3 \mathrm{cmH}_{2} \mathrm{O} / \mathrm{L} / \mathrm{sec}$ as borderline, and those $\geq 3$ $\mathrm{cmH}_{2} \mathrm{O} / \mathrm{L} / \mathrm{s}$ as highly resistant $[12,13]$. At lower frequencies, the value of Rrs is greater; consequently, patients with COPD tend to have a greater R5 - R20, which is thought to reflect heterogeneous ventilatory mechanics [14]. Xrs is the imaginary part of respiratory impedance and includes the mass inertial forces of the moving air column, expressed in terms of inertia, and the elastic properties or compliance of the lung periphery, expressed as capacitance. The reactance at $5 \mathrm{~Hz}$ (X5) reflects the combined effects of tissue elastance and inertia, although at this lower frequency, the effect of tissue elastance would be predominant. X5 therefore reflects the elastic recoil of the peripheral airways $[9,15]$. Because the ability of the lungs to store capacitative energy is primarily manifest in the small airways, X5 can provide important information about the distal/small airways. States that reduce the elasticity of the lungs, such as fibrosis and hyperinflation, make the capacitance more negative, with more negative or higher $\mathrm{X} 5$ values [10]. The resonant frequency (Fres) is the frequency at which respiratory reactance equals $0 \mathrm{cmH}_{2} \mathrm{O} / \mathrm{L} /$ $\mathrm{s}$. Fres marks the transition from capacitative dominance at low frequencies to inertial dominance at high frequencies. This also helps conveniently categorize frequencies below Fres as low and above Fres as high, and indicates a frequency at which the total impedance to airflow is completely resistive. Normal Fres is approximately 6-11 Hz. Fres tends to be higher in children, decreases with age and increases in individuals with both obstructive and restrictive diseases [10]. The area of low reactance (ALX) is the area created by three lines (that of frequency $5 \mathrm{~Hz}, \mathrm{Xrs}=0$ $\mathrm{cmH}_{2} \mathrm{O} / \mathrm{L} / \mathrm{s}$ and the Xrs curve). ALX is a useful index associated with respiratory compliance and therefore of the patency of the small airways. ALX is a single quantity that reflects changes in the degree of peripheral airway obstruction and closely correlates with R5 - R20. Normal ALX is generally $<0.33 \mathrm{kPa} / \mathrm{L}\left(<3.37 \mathrm{cmH}_{2} \mathrm{O} / \mathrm{L}\right)$ [10]. A preliminary study with the MostGraph-01 showed the details of these parameters (Fig. 1a, b). The mean of each FOT parameter was calculated during approximately five respiratory cycles, including the inspiratory and expiratory phases. This technique may be more helpful than spirometry in evaluating the respiratory differences between preoperative and postoperative status, because respiratory impedance can be measured without any effort by the patient and airway narrowing can be detected. Furthermore, assessing the relationships between preoperative spirometry results and pre- and postoperative FOT measurements may help determine whether preoperative spirometry results can predict postoperative deterioration of respiratory impedance.

This study therefore examined the effects of tracheal intubation, inhalational general anesthesia and mechanical ventilation on perioperative respiratory impedance measured using FOT. In addition, the relationships between respiratory function measured by spirometry and respiratory impedance measured by FOT were evaluated. 

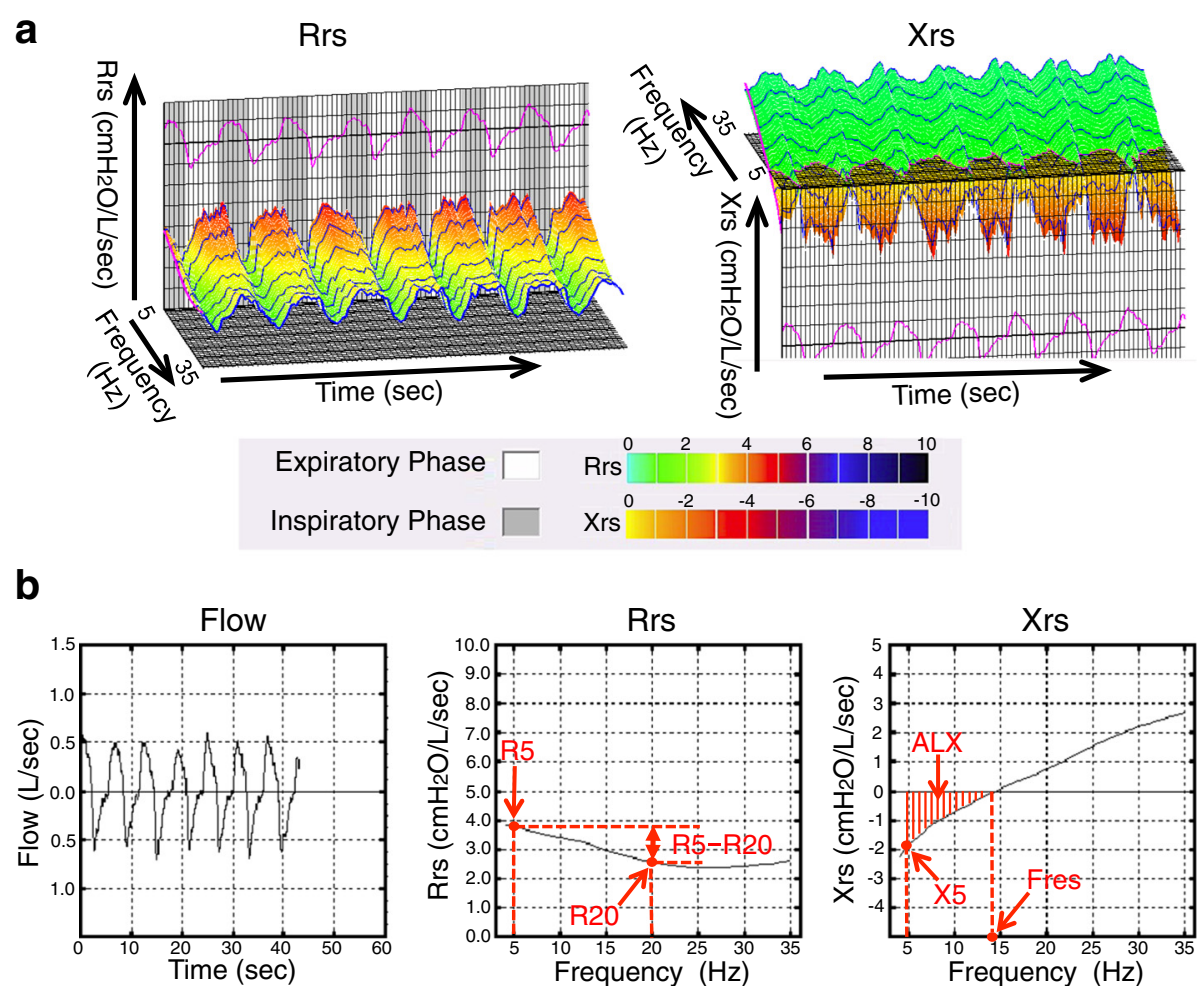

Fig. 1 a Representative 3D color graph of postoperative respiratory resistance and reactance, measured using the MostGraph-01. The $x-$, $y$-, and z-axes show time, respiratory resistance (Rrs) or respiratory reactance (Xrs), and frequency $(5-35 \mathrm{~Hz})$, respectively. b Representative 2D graph of postoperative respiratory resistance and respiratory reactance measured using the MostGraph-01. Respiratory resistance (Rrs) was measured at $5 \mathrm{~Hz}$ (R5) and $20 \mathrm{~Hz}$ (R20), and their difference was calculated (R5 - R20; frequency dependence of respiratory resistance). Respiratory reactance (Xrs) was measured at $5 \mathrm{~Hz}$ (X5), as were Fres (frequency at a respiratory reactance of $0 \mathrm{~cm} \mathrm{H} \mathrm{H}_{2} \mathrm{O} / \mathrm{L} / \mathrm{s}$ ) and area of low respiratory reactance (ALX, the area made by three lines of frequency $5 \mathrm{~Hz}$, Xrs $=0 \mathrm{cmH}_{2} \mathrm{O} / \mathrm{L} / \mathrm{s}$ and the Xrs curve). Rrs and Xrs represent the average values of inspiratory and expiratory phases, respectively

\section{Methods}

The study protocol was approved by the Ethics Committee of Osaka Medical College (reference number 1252), and all participants provided written informed consent. This prospective observational study assessed a cohort of 30 patients scheduled for transurethral resection of a bladder tumor under general anesthesia. Patients diagnosed with COPD, according to the Global Initiative for Chronic Obstructive Lung Disease (GOLD) guidelines [16], were excluded, as were patients with a history or symptoms of asthma, such as cough or wheeze at rest, and patients who had taken oral steroids or had a respiratory tract infection or exacerbation within the previous 3 months. Respiratory resistance (R5, R20 and R5 - R20) and reactance (X5, Fres and ALX) parameters were measured using the MostGraph-01 on the day before surgery. FOT measurements were made on patients sitting with their necks in a comfortable neutral posture; patients also wore a nose clip, and their cheeks were supported firmly. Participants were instructed to breath normally at functional residual capacity level (tidal breathing) for $30 \mathrm{~s}$ [9]. Spirometry was performed within 1 week before surgery using a spirometer (System 21 device, Minato
Ikagaku, Osaka, Japan). Parameters measured included vital capacity (VC), forced vital capacity (FVC) and forced expiratory volume in the first second (FEV1.0).

Anesthesia was induced with intravenous propofol $1.5 \mathrm{mg} / \mathrm{kg}$, rocuronium $1 \mathrm{mg} / \mathrm{kg}$, a continuous infusion of remifentanil at $0.4 \mu \mathrm{g} / \mathrm{kg} / \mathrm{min}$ and inhaled sevoflurane $3.0 \%$. The trachea was intubated with a tube of internal diameter $7.0 \mathrm{~mm}$ for women and $8.0 \mathrm{~mm}$ for men (Portex, Smiths Medical, Tokyo, Japan). Anesthesia was maintained with inhaled sevoflurane $1.2 \%$, intravenous remifentanil $0.25 \mu \mathrm{g} / \mathrm{kg} / \mathrm{min}$ and intravenous rocuronium $0.4 \mu \mathrm{g} / \mathrm{kg} / \mathrm{min}$. The lungs were ventilated with a 0.4 fraction of inspired oxygen; a tidal volume of $7 \mathrm{ml} / \mathrm{kg}$ predicted ideal body weight with a positive end-expiratory pressure (PEEP) of $5 \mathrm{cmH}_{2} \mathrm{O}$. If oxygen saturation measured by pulse oximetry was $<97 \%$, the tidal volume was increased to $8.5 \mathrm{ml} / \mathrm{kg}$ and more PEEP was added. At the end of surgery, patients were administered $1000 \mathrm{mg}$ intravenous acetaminophen for pain relief, followed by $1.5 \mathrm{mg} / \mathrm{kg}$ intravenous sugammadex. Tracheal suctioning was performed once or twice before patients were extubated. The tracheal tube was removed when patients could breathe spontaneously with sufficient tidal volume 
and were able to communicate. Supplementary oxygen at $6 \mathrm{l} / \mathrm{min}$ was administered by a face-mask immediately after extubation. Respiratory impedance was measured within minutes after extubation using the MostGraph-01, with the patients in the Farrar position (sitting position with $45-50^{\circ}$ head up-tilt).

Pre- and postoperative FOT measurements were compared, as were the relationships between those parameters and preoperative spirometry results. Postoperative FOT measurements were not performed in patients who became restless or nauseated.

This study was registered as a clinical study in a Japanese official clinical trial registry (JMACCT). The trial registration number was JMA-IIA00136.

\section{Statistical analysis}

Patient characteristics were expressed as median with interquartile range (IQR). Pre- and postoperative respiratory impedance measurements were compared using Wilcoxon paired rank tests, with $p<0.01$ considered statistically significant. The relationships between spirometry findings and respiratory impedance were assessed using Spearman's rank correlation, with $p<0.01$ considered statistically significant. All statistical analyses were performed using GraphPad Prism 6 software (GraphPad Software, La Jolla, CA).

\section{Results}

Postoperative FOT measurements could not be made in four patients because of restlessness in three and nausea in one; therefore, 26 patients were included in the final analysis. None of these patients experienced any serious perioperative events and none required administration of atropine. Oxygen saturation remained $>97 \%$ in all patients. The characteristics of the 26 patients included in the analysis are shown in Table 1.

The median (IQR) of preoperative R5, R20, R5 - R20, $\mathrm{X} 5$, Fres and ALX were 2.40 (1.79 to 2.78$) \mathrm{cmH}_{2} \mathrm{O} / \mathrm{L} / \mathrm{s}$, 1.76 (1.48 to 2.22) $\mathrm{cmH}_{2} \mathrm{O} / \mathrm{L} / \mathrm{s}, 0.61$ (0.41 to 0.74 ) $\mathrm{cmH}_{2} \mathrm{O} / \mathrm{L} / \mathrm{s},-0.46$ (-1.10 to -0.25$) \mathrm{cmH}_{2} \mathrm{O} / \mathrm{L} / \mathrm{s}, 8.82$ (6.76 to 12.13$) \mathrm{Hz}$, and 1.60 (0.82 to 5.69$) \mathrm{cmH}_{2} \mathrm{O} / \mathrm{L}$, respectively. Postoperative R5, R20, R5 - R20, X5, Fres and ALX were 4.07 (3.35 to 5.32) $\mathrm{cmH}_{2} \mathrm{O} / \mathrm{L} / \mathrm{s}, 3.04$ (2.59 to 3.86) $\mathrm{cmH}_{2} \mathrm{O} / \mathrm{L} / \mathrm{s}, 1.07$ (0.73 to 1.52$) \mathrm{cmH}_{2} \mathrm{O} / \mathrm{L} / \mathrm{s},-2.16$ (-3.15 to -0.94$) \mathrm{cmH}_{2} \mathrm{O} / \mathrm{L} / \mathrm{s}, 14.39$ (10.79 to 17.69$) \mathrm{Hz}$ and 12.11 (4.34 to 22.34) $\mathrm{cmH}_{2} \mathrm{O} / \mathrm{L}$, respectively. All components of resistance deteriorated significantly over the course of surgery, with median increases in R5, $\mathrm{R} 20$, and $\mathrm{R} 5-\mathrm{R} 20$ of $1.67 \mathrm{cmH}_{2} \mathrm{O} / \mathrm{L} / \mathrm{s}(p<0.0001), 1.28$ $\mathrm{cmH}_{2} \mathrm{O} / \mathrm{L} / \mathrm{s}(p<0.0001)$ and $0.46 \mathrm{cmH}_{2} \mathrm{O} / \mathrm{L} / \mathrm{s}(p=0.0004)$, respectively. The components of reactance also deteriorated significantly, with $\mathrm{X} 5$ decreasing $1.7 \mathrm{cmH}_{2} \mathrm{O} / \mathrm{L} / \mathrm{s}$ $(p<0.0001)$, Fres increasing $5.57 \mathrm{~Hz}(p<0.0001)$ and ALX increasing $10.51 \mathrm{cmH}_{2} \mathrm{O} / \mathrm{L}(p<0.0001)$ (Fig. 2).
Table 1 Baseline demographic and clinical characteristics of the patient cohort

\begin{tabular}{|c|c|}
\hline Preoperative parameter & $N=26$ \\
\hline Male & $23(88.5 \%)$ \\
\hline Age (years) & 68 (55 to 74$)$ \\
\hline Height $(\mathrm{cm})$ & 163.5 (160.6 to 168.9$)$ \\
\hline Weight (kg) & $62.1(56.8$ to 69.1$)$ \\
\hline Body mass index $\left(\mathrm{kg} / \mathrm{m}^{2}\right)$ & 23.7 (21.0 to 25.8$)$ \\
\hline Body surface area $\left(\mathrm{m}^{2}\right)$ & 1.7 (1.6 to 1.7$)$ \\
\hline Non-smoker & $4(15.4 \%)$ \\
\hline Smoker & $5(19.2 \%)$ \\
\hline Ex-smoker & $17(65.4 \%)$ \\
\hline Brinkman index & $630(300$ to 1105$)$ \\
\hline $\mathrm{VC}(\mathrm{L})$ & 3.1 (2.8 to 3.8$)$ \\
\hline$\%$ VC (\% predicted) & $101.4(87.2$ to 112.5$)$ \\
\hline $\mathrm{FVC}(\mathrm{L})$ & 3.0 (2.7 to 3.8$)$ \\
\hline$\% F V C$ (\% predicted) & 98 (86.8 to 111.5$)$ \\
\hline FEV1.0 (L) & 2.3 (1.7 to 2.7$)$ \\
\hline \%FEV1.0 (\% predicted) & $74.3(67.6$ to 80.4$)$ \\
\hline FEV1.0/FVC ratio (\%) & $74.3(67.6$ to 80.4$)$ \\
\hline Anesthetic time (min) & 89 (73 to 99$)$ \\
\hline Operating time (min) & 47 (35 to 56$)$ \\
\hline Intravenous fluid volume (ml) & 650 (588 to 700$)$ \\
\hline
\end{tabular}

Data are expressed as median (interquartile range) or as number (percent). Brinkman index, defined as the number of cigarettes smoked per day multiplied by smoking years, was calculated in smokers and ex-smokers only. Preoperative spirometry data were measured within 1 week before surgery Abbreviations: VC vital capacity, FVC forced vital capacity, FEV1.0 forced expiratory volume in the first second

The relationships between preoperative spirometry and preoperative FOT findings are shown in Table 2. The preoperative predicted vital capacity $(\% \mathrm{VC})$ correlated significantly with $\mathrm{X} 5(p=0.0013)$, Fres $(p=0.0001)$ and $\operatorname{ALX}(p=0.0008)$. In addition, predicted forced expiratory volume in $1 \mathrm{~s}$ (\%FEV1.0) correlated significantly with X5 $(p=0.0058)$, Fres $(p=0.0022)$ and ALX $(p=0.0030)$. Moreover, predicted forced vital capacity (\%FVC) correlated significantly with X5 $(p=0.0033)$, Fres $(p=0.0012)$ and $\operatorname{ALX}(p=0.0022)$.

Statistically significant relationships were also observed between the same three preoperative spirometry parameters (\%VC, \%FEV1.0 and \%FVC) and postoperative respiratory reactance (X5, Fres and ALX), as shown in Table 3. Preoperative predicted vital capacity (\%VC) correlated significantly with X5 $(p=0.0002)$, Fres $(p<0.0001)$ and $\operatorname{ALX}(p<0.0001)$. \%FEV1.0 also correlated significantly with X5, Fres and ALX $(p<0.0001$ each), and \%FVC correlated significantly with X5 $(p=0.0001)$, Fres $(p<0.0001)$ and $\operatorname{ALX}(p<0.0001)$. 


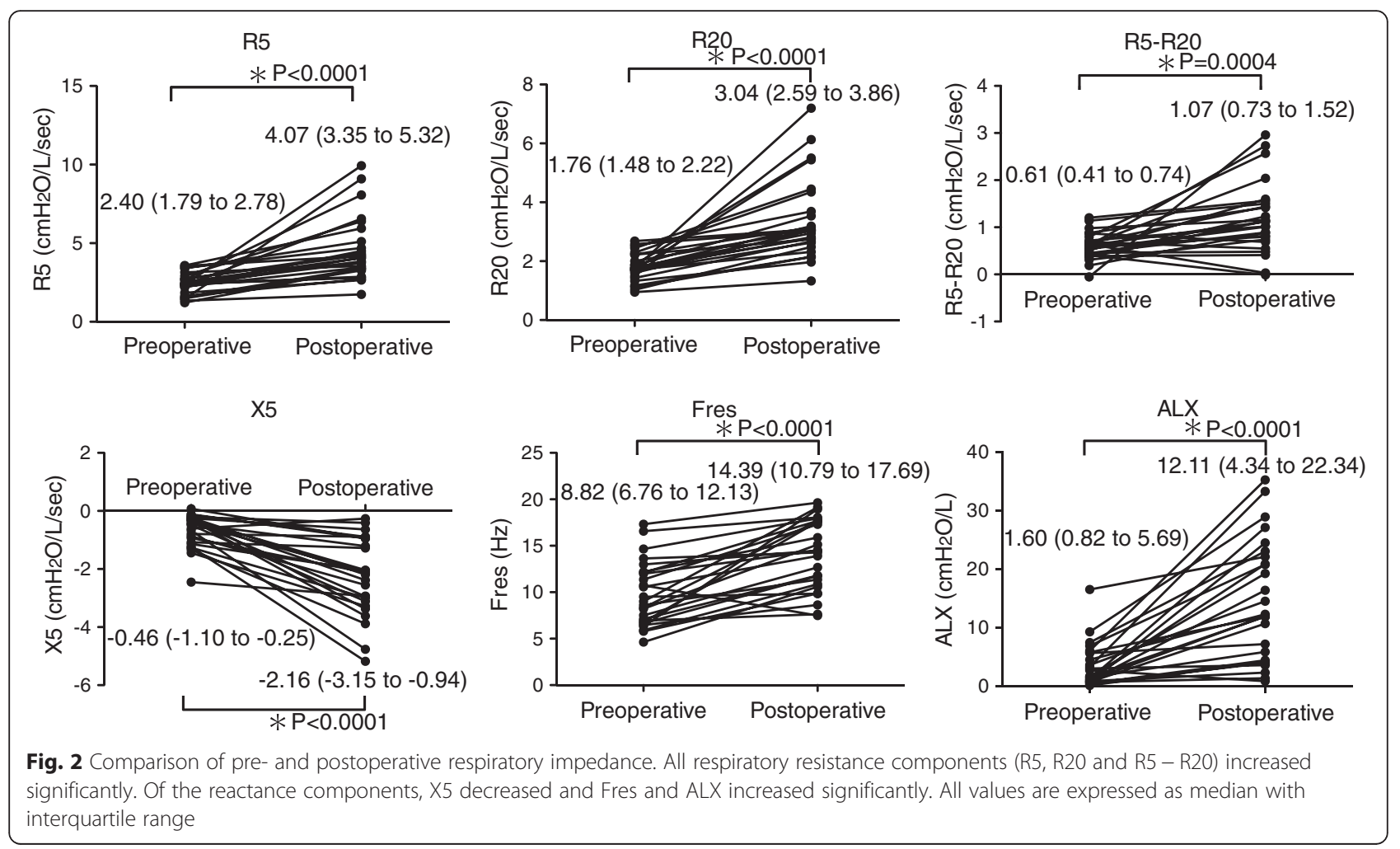

\section{Discussion}

This study, which compared preoperative and postoperative measures by FOT, found that respiratory impedance deteriorated dramatically after anesthesia. To our knowledge, this is the first study to report postoperative FOT measurements immediately after anesthesia. All three components of Rrs (R5, R20 and R5-R20) increased. Assessments of Xrs showed that X5 decreased while Fres and ALX increased. The deterioration in respiratory impedance increased with a longer period of anesthesia [11]. Anesthesia and mechanical ventilation reduce respiratory compliance, increase Rrs, and cause atelectasis and airway closure, resulting in shunt [17]. This study, however, focused on perioperative changes in respiratory impedance, thought to be caused by: 1) edema of the vocal folds, resulting from endotracheal intubation; 2) proximal and peripheral airway edema, resulting from administration of excess intravenous fluid and/or the Trendelenburg position; 3) sputum (i.e. mucous secreted by the lungs, bronchi and trachea that can include oral discharge); 4) asthma; and/or 5) ventilator-induced lung injury (VILI) [18]. In this study, patients were in the lithotomy position without head-down tilt during surgery. Moreover, the volume of intraoperative intravenous fluid administered was not regarded as excessive because the operation time was relatively short. We also adopted a lung protection strategy for mechanical ventilation by selecting a tidal volume of $7 \mathrm{ml} / \mathrm{kg}$ and a PEEP of $5 \mathrm{cmH}_{2} \mathrm{O}$ to minimize lung injury $[18,19]$, although the I:E ratio in all patients was 1:2 [20]. Nonetheless, in our cohort, deterioration in

Table 2 Relationships between spirometry and preoperative FOT findings

\begin{tabular}{|c|c|c|c|c|c|c|c|c|}
\hline & \multicolumn{2}{|l|}{$\% \mathrm{VC}$} & \multicolumn{2}{|l|}{ \%FEV1.0 } & \multicolumn{2}{|l|}{$\% \mathrm{FVC}$} & \multicolumn{2}{|c|}{ FEV1.0/FVC ratio } \\
\hline & Coefficient & $p$ value & Coefficient & $p$ value & Coefficient & $p$ value & Coefficient & $p$ value \\
\hline Preoperative $\mathrm{R} 5\left(\mathrm{cmH}_{2} \mathrm{O} / \mathrm{L} / \mathrm{s}\right)$ & -0.371 & 0.0623 & -0.381 & 0.0551 & -0.319 & 0.1129 & -0.222 & 0.2751 \\
\hline Preoperative R20 $\left(\mathrm{cmH}_{2} \mathrm{O} / \mathrm{L} / \mathrm{s}\right)$ & -0.326 & 0.1036 & -0.338 & 0.0915 & -0.294 & 0.1455 & -0.167 & 0.4139 \\
\hline Preoperative R5-R20 $\left(\mathrm{cmH}_{2} \mathrm{O} / \mathrm{L} / \mathrm{s}\right)$ & -0.268 & 0.1855 & -0.340 & 0.0897 & -0.191 & 0.3505 & -0.354 & 0.0758 \\
\hline Preoperative $\times 5\left(\mathrm{cmH}_{2} \mathrm{O} / \mathrm{L} / \mathrm{s}\right)$ & 0.595 & $0.0013^{*}$ & 0.526 & $0.0058^{*}$ & 0.555 & $0.0033^{*}$ & 0.176 & 0.3911 \\
\hline Preoperative Fres $(\mathrm{Hz})$ & -0.642 & $0.0001 *$ & -0.573 & $0.0022^{*}$ & -0.599 & $0.0012^{*}$ & -0.227 & 0.2640 \\
\hline Preoperative $\mathrm{ALX}\left(\mathrm{cmH}_{2} \mathrm{O} / \mathrm{L}\right)$ & -0.615 & $0.0008^{*}$ & -0.558 & $0.0030^{*}$ & -0.573 & $0.0022^{*}$ & -0.221 & 0.2790 \\
\hline
\end{tabular}

Abbreviations: $R 5$ respiratory resistance at $5 \mathrm{~Hz}, R 20$ respiratory resistance at $20 \mathrm{~Hz}, X 5$ respiratory reactance at $5 \mathrm{~Hz}$, Fres resonance frequency, $A L X$ area of low respiratory reactance, $V C$ vital capacity, FVC forced vital capacity, FEV1.0 forced expiratory volume in the first second. ${ }^{*} P<0.01$ 
Table 3 Relationships between spirometry and postoperative FOT findings

\begin{tabular}{|c|c|c|c|c|c|c|c|c|}
\hline & \multicolumn{2}{|l|}{$\% \mathrm{VC}$} & \multicolumn{2}{|l|}{ \%FEV1.0 } & \multicolumn{2}{|l|}{$\% F V C$} & \multicolumn{2}{|c|}{ FEV1.0/FVC ratio } \\
\hline & Coefficient & $p$ value & Coefficient & $p$ value & Coefficient & $p$ value & Coefficient & $p$ value \\
\hline Postoperative $\mathrm{R} 5\left(\mathrm{cmH}_{2} \mathrm{O} / \mathrm{L} / \mathrm{s}\right)$ & -0.285 & 0.1585 & -0.290 & 0.1513 & -0.262 & 0.1968 & -0.097 & 0.6358 \\
\hline Postoperative R20 $\left(\mathrm{cmH}_{2} \mathrm{O} / \mathrm{L} / \mathrm{s}\right)$ & -0.180 & 0.3785 & -0.283 & 0.1617 & -0.171 & 0.4028 & -0.197 & 0.3358 \\
\hline Postoperative R5-R20 ( $\left.\mathrm{cmH}_{2} \mathrm{O} / \mathrm{L} / \mathrm{s}\right)$ & -0.437 & 0.0256 & -0.320 & 0.1113 & -0.396 & 0.0450 & 0.029 & 0.8866 \\
\hline Postoperative $\mathrm{X} 5\left(\mathrm{cmH}_{2} \mathrm{O} / \mathrm{L} / \mathrm{s}\right)$ & 0.672 & $0.0002 *$ & 0.720 & $<0.0001^{*}$ & 0.684 & $0.0001 *$ & 0.336 & 0.0935 \\
\hline Postoperative Fres $(\mathrm{Hz})$ & -0.742 & $<0.0001^{*}$ & -0.708 & $<0.0001^{*}$ & -0.741 & $<0.0001 *$ & -0.229 & 0.2602 \\
\hline Postoperative $\mathrm{ALX}\left(\mathrm{cmH}_{2} \mathrm{O} / \mathrm{L}\right)$ & -0.699 & $<0.0001^{*}$ & -0.734 & $<0.0001^{*}$ & -0.706 & $<0.0001^{*}$ & -0.335 & 0.0939 \\
\hline
\end{tabular}

Abbreviations: $R 5$ respiratory resistance at $5 \mathrm{~Hz}, R 20$ respiratory resistance at $20 \mathrm{~Hz}, X 5$ respiratory reactance at $5 \mathrm{~Hz}$, Fres resonance frequency, ALX area of low respiratory reactance, VC vital capacity, FVC forced vital capacity, FEV1.0 forced expiratory volume in the first second. ${ }^{*} P<0.01$

respiratory function was likely caused by a combination of these factors, including very mild VILI during surgery in the Trendelenburg position and stimulation by intubation, extubation, and tracheal suctioning. The factor having the greatest influence was unclear. A study using endotracheal intubation and a subglottic device for airway management may determine the influence of tracheal intubation and extubation, whereas a study with or without endotracheal suctioning may determine the influence of stimulation by suctioning. Use of a tracheal tube and endotracheal suctioning can cause coughing, although all patients probably experienced very mild VILI caused by mechanical ventilation with high and/or low lung volume. Our findings suggest that measuring Rrs can help to understand respiratory compliance during mechanical ventilation and to detect VILI caused by overdistension of the lungs and/ or atelectrauma. A comparison of Rrs before and after alveolar recruitment maneuvers (ARMs) can determine the effect of ARM on VILI. Recommended ARM generally consists of holding the lungs at $40 \mathrm{cmH}_{2} \mathrm{O}$ for more than 7-8 s during mechanical ventilation [21]. Rrs can be measured only during the expiratory phase of volumecontrolled ventilation under anesthesia, with a simple modification of the FOT speaker of MostGraph-01. It may not be possible, however, to correctly measure Xrs during mechanical ventilation.

We observed that the components of Xrs correlated with \%VC and \%FEV1.0. Low \%VC indicates a restrictive lung disorder, whereas low \%FEV1.0 indicates an obstructive disorder. Reductions in X5 and increases in Fres and ALX are expected when respiratory compliance decreases. FOT has been reported to be more sensitive than spirometry in detecting obstructive pulmonary disease and in assessing the effects of bronchodilators [22-25]. However, because of difficulties interpreting Xrs, we could not clearly determine the relationships between spirometry and FOT measurements.

Changes in respiratory function were measured after transurethral bladder tumor resection under general anesthesia. This operation was chosen because operating time is relatively brief and predictable, there is little postoperative pain, patients are able to sit up relatively quickly afterwards, there is little blood loss or fluid shift, and surgery does not affect ventilatory strategy. The main advantages of FOT are that minimal cooperation is required from the patients and no respiratory maneuvers are needed. Therefore, respiratory impedance should be measured whenever spirometry cannot be performed or would likely be unreliable. In addition, although the MostGraph-01 recording technique is well established, the extent of cheek support may influence respiratory impedance, as it can affect upper airway artifacts [26].

Future studies should focus on establishing the time course of postoperative recovery of respiratory impedance and the effects of treatments. FOT can also be used to determine the need for postoperative interventions and physical therapy in severe cases. Furthermore, differences in respiratory impedance measured during the inspiratory and expiratory phases may help illuminate the underlying mechanisms [23-27]. The influence of anesthesia on respiratory impedance in patients with peripheral airway inflammation should also be assessed. Measurement of fractional exhaled nitric oxide, a surrogate marker of eosinophilic airway inflammation [24, 25, 28, 29], may also enhance understanding of the relationships between biochemical and physiologic influences on respiratory function.

This study had several limitations. First, it did not compare postoperative FOT measurements with postoperative spirometry measurements, because performing postoperative spirometry on the day of surgery carries a risk of bleeding from the bladder. Furthermore, the study design did not include standardization of the administration of fluids and use of bladder irrigation. Limiting fluid volume likely would not have affected our results, because transurethral resection of bladder tumors is of short duration and minimally invasive. Bladder irrigation was not determined. None of these patients experienced transurethral resection (TUR) syndrome or 
intra- or postoperative hypoxia. However, a surgical procedure that does not have to assess the influence of fluid shifts is ideal for investigating respiratory mechanisms. Another limitation of our study was the relatively small sample size. Further studies are needed to better evaluate changes in perioperative respiratory mechanics.

\section{Conclusions}

All parameters of respiratory resistance and reactance deteriorated significantly after general anesthesia and mechanical ventilation. Components of resistance (R5, R20 and R5-R20) increased, while, of the reactance components, X5 decreased and Fres and ALX increased. Pre- and postoperative respiratory reactance correlated with preoperative pulmonary function measured by spirometry. Measuring FOT with MostGraph-01 is a straightforward means of measuring perioperative changes in respiratory impedance and has the potential to determine respiratory compliance effected by general anesthesia.

\section{Abbreviations}

\%FEV1.0, predicted percent forced expiratory volume in the first second; \%FVC, percent forced vital capacity; \%VC, predicted percent vital capacity; ALX, area of low reactance; COPD, chronic obstructive pulmonary disease; FEV1.0, forced expiratory volume in one second; FOT, forced oscillation technique; Fres, resonant frequency; FVC, forced vital capacity; IQR, interquartile range; PEEP, positive end-expiratory pressure; $\mathrm{R} 20$, respiratory resistance at $2 \mathrm{OHz}$; $\mathrm{R} 5-\mathrm{R} 2 \mathrm{O}$, difference between R5 and R2O; R5, respiratory resistance at $5 \mathrm{~Hz}$; Rrs, respiratory resistance; VC, vital capacity; VILI, ventilator induced lung injury; $X 5$, reactance at $5 \mathrm{~Hz}$; Xrs, respiratory reactance

\section{Acknowledgements}

None.

\section{Funding}

This work was supported in part by KAKENHI (Grants-in-Aid for Scientific Research) from the Japan Society for the Promotion of Science.

\section{Availability of data and materials}

The datasets supporting the conclusion of this article are included within this article

\section{Authors' contributions}

SN participated in the design and coordination of the study and helped draft the manuscript. JN made substantial contributions to the conception and design of the study and the acquisition of data, and drafted the manuscript. TS performed the statistical analyses and revised the manuscript critically for important intellectual content. YK and JI made substantial contributions to the conception of the study and helped correct the manuscript. TM made substantial contributions to the conception of the study and helped draft the manuscript. All authors have read and approved the final manuscript.

\section{Competing interests}

The authors declare that they have no competing interests.

\section{Consent for publication}

All authors agreed to publish this research article.

\section{Ethics approval and consent to participants}

The study protocol was approved by the Ethics Committee of Osaka Medical College (reference number 1252), and all participants provided written informed consent.

Received: 23 June 2015 Accepted: 17 June 2016 Published online: 07 July 2016

\section{References}

1. Oostveen E, MacLeod D, Lorino H, Farré R, Hantos Z, Desager K, Marchal F. ERS task force on respiratory impedance measurements. The forced oscillation technique in clinical practice: methodology, recommendations and future developments. Eur Respir J. 2003;22:1026-41.

2. MacLeod D, Birch M. Respiratory input impedance measurement: forced oscillation methods. Med Biol Eng Comput. 2001;39:505-16.

3. Kanda S, Fujimoto K, Komatsu Y, Yasuo M, Hanaoka M, Kubo K. Evaluation of respiratory impedance in asthma and COPD by an impulse oscillation system. Intern Med. 2010;49:23-30.

4. Yamaguchi M, Niimi A, Ueda T, Takemura M, Matsuoka H, Jinnai M, Otsuka K, Oguma T, Takeda T, Ito I, Matsumoto H, Hirai T, Chin K, Mishima M. Effect of inhaled corticosteroids on small airways in asthma: investigation using impulse oscillometry. Pulm Pharmacol Ther. 2009;22:326-32.

5. Mori K, Shirai T, Mikamo M, Shishido Y, Akita T, Morita S, Asada K, Fujii M, Suda T, Chida K. Colored 3-dimensional analyses of respiratory resistance and reactance in COPD and asthma. COPD. 2011;8:456-63.

6. Paredi P, Goldman M, Alamen A, Ausin P, Usmani OS, Pride NB, Barnes PJ. Comparison of inspiratory and expiratory resistance and reactance in patients with asthma and chronic obstructive pulmonary disease. Thorax. 2010;65:263-7.

7. Kurosawa H, Ohishi J, Shimizu Y, Tasaku Y, Kobayashi D, Masuda M, Kanezaki M, Nikkuni E, Kohzuki M, Hida W. A new method to assess lung volume dependency of respiratory system resistance using forced oscillation. Am J Respir Crit Care Med. 2010;181:A1240.

8. LaPrad AS, Lutchen KR. Respiratory impedance measurements for assessment of lung mechanics: focus on asthma. Respir Physiol Neurobiol. 2008;163:64-73.

9. Shirai T, Mori K, Mikamo M, Shishido Y, Akita T, Morita S, Asada K, Fujii M, Suda T, Chida K. Usefulness of colored 3D imaging of respiratory impedance in asthma. Allergy, Asthma Immunol Res. 2013;5:322-8.

10. Brashier B, Salvi S. Measuring lung function using sound waves: role of the forced oscillation technique and impulse oscillometry system. Breathe (Sheff). 2015;11:57-65.

11. Kuzukawa Y, Nakahira J, Sawai T, Minami T. A perioperative evaluation of respiratory mechanics using the forced oscillation technique. Anesth Analg. 2015;121:1202-6.

12. Shiota S, Katoh M, Fujii M, Aoki S, Matsuoka R, Fukuchi Y. Predictive equations and the reliability of the impulse oscillatory system in Japanese adult subjects. Respirology. 2005;10:310-5.

13. Kurosawa H. Mostgraph: development and applications. Kokyu. 2010;29:40-7.

14. Dellacà RL, Pompilio PP, Walker PP, Duffy N, Pedotti A, Calverley PM. Effect of bronchodilation on expiratory flow limitation and resting lung mechanics in COPD. Eur Respir J. 2009;33:1329-37.

15. Komarow HD, Myles IA, Uzzaman A, Metcalfe DD. Impulse oscillometry in the evaluation of diseases of the airways in children. Ann Allergy Asthma Immunol. 2011;106:191-9.

16. From the Global Strategy for the Diagnosis, Management and Prevention of COPD, Global Initiative for Chronic Obstructive Lung Disease (GOLD) 2015. http://www.goldcopd.org. Accessed 22 May 2015.

17. Kavanagh BP, Hedenstierna G. Respiratory physiology and pathophysiology. In: Miller RD, Eriksson LI, Fleisher LA, Wiener-Kronish JP, Cohen NH, Young WL, editors. Miller's Anesthesia. 8th ed. Philadelphia: Saunders; 2014. p. 444-72.

18. Slutsky AS, Ranieri VM. Ventilator-induced lung injury. N Engl J Med. 2013; 369:2126-36.

19. Seah AS, Grant KA, Aliyeva M, Allen GB, Bates JH. Quantifying the roles of tidal volume and PEEP in the pathogenesis of ventilatorinduced lung injury. Ann Biomed Eng. 2011;39:1505-16.

20. Müller-Redetzky HC, Felten M, Hellwig K, Wienhold SM, Naujoks J, Opitz B, Kershaw O, Gruber AD, Suttorp N, Witzenrath M. Increasing the inspiratory time and I:E ratio during mechanical ventilation aggravates ventilatorinduced lung injury in mice. Crit Care. 2015;19:23.

21. Rothen HU, Neumann P, Berglund JE, Valtysson J, Magnusson A, Hedenstierna G. Dynamics of re-expansion of atelectasis during general anaesthesia. Br J Anaesth. 1999;82:551-6.

22. Borrill ZL, Houghton CM, Woodcock AA, Vestbo J, Singh D. Measuring bronchodilation in COPD clinical trials. Br J Clin Pharmacol. 2005:59:379-84.

23. Van Noord JA, Smeets J, Clément J, Van de Woestijne KP, Demedts M. Assessment of reversibility of airflow obstruction. Am J Respir Crit Care Med. 1994;150:551-4. 
24. Houghton CM, Woodcock AA, Singh D. A comparison of lung function methods for assessing dose-response effects of salbutamol. Br J Clin Pharmacol. 2004;58:134-41.

25. Yaegashi M, Yalamanchili VA, Kaza V, Weedon J, Heurich AE, Akerman MJ. The utility of the forced oscillation technique in assessing bronchodilator responsiveness in patients with asthma. Respir Med. 2007;101:995-1000.

26. Uchida A, Ito S, Suki B, Matsubara H, Hasegawa Y. Influence of cheek support on respiratory impedance measured by forced oscillation technique. Springerplus. 2013;2:342.

27. Shirai T, Mori K, Mikamo M, Shishido Y, Akita T, Morita S, Asada K, Fujii M, Suda T, Chida K. Respiratory mechanics and peripheral airway inflammation and dysfunction in asthma. Clin Exp Allergy. 2013;43:521-6.

28. Matsumoto H, Niimi A, Jinnai M, Nakaji H, Takeda T, Oguma T, Otsuka K, Inoue H, Yamaguchi M, Matsuoka H, Ito I, Hirai T, Chin K, Mishima M. Association of alveolar nitric oxide levels with pulmonary function and its reversibility in stable asthma. Respiration. 2011;81:311-7.

29. Williamson PA, Clearie K, Menzies D, Vaidyanathan S, Lipworth BJ. Assessment of small-airways disease using alveolar nitric oxide and impulse oscillometry in asthma and COPD. Lung. 2011;189:121-9.

\section{Submit your next manuscript to BioMed Central} and we will help you at every step:

- We accept pre-submission inquiries

- Our selector tool helps you to find the most relevant journal

- We provide round the clock customer support

- Convenient online submission

- Thorough peer review

- Inclusion in PubMed and all major indexing services

- Maximum visibility for your research

Submit your manuscript at www.biomedcentral.com/submit 